\title{
A New Strategy for Energy Saving in Spectrum-Sliced Elastic Optical Networks
}

\author{
Igor M. Queiroz * and Karcius D. R. Assis * \\ Department of Electrical and Computer Engineering, Federal University of Bahia, Salvador 40210-630, Brazil \\ * Correspondence: igor.m.queiroz@ieee.org (I.M.Q.); karcius.assis@ufba.br (K.D.R.A.); \\ Tel.: +55-71-3283-9760 or 92-99109-9902 \\ † This paper is an extended version of our paper published in the 9th Computer Science \& Electronic \\ Engineering Conference (CEEC), Colchester, UK, 27-29 September 2017.
}

Received: 10 April 2018; Accepted: 9 May 2018; Published: 11 May 2018

\begin{abstract}
In this paper, we propose a new approach for energy saving in Elastic Optical Networks (EONs) under physical impairments based on MILP solving instances. First, we seek to maximize the attended traffic on the network whereas the blocking probability is maintained below a defined limit. Hence, the next step is to minimize the power consumption on the network. The proposed MILP-based algorithm models the RMLSA problem and considers transponders, optical cross-connects (OXCs), and optical amplifiers as the physical components with influence on network optimization. The results show that our approach offers, on average, a reduction of up to $7.7 \%$ of the power consumed on the four moderate networks analyzed.
\end{abstract}

Keywords: elastic optical networks; energy saving; green optical networks; routing modulation and spectral assignment; MILP formulation; optimization

\section{Introduction}

WDM (Wavelength Division Multiplexing) transmission systems emerged in the late 70s to deal with the mismatch between the capacity of the transmission/reception of electrical transceivers (on the order of a few gigabits per second-Gbps) and the available bandwidth in optical fibers (of the order of a few terahertz-THz) [1]. Due to its simplicity and low cost, WDM technology was immediately used in peer-to-peer systems, first-generation optical networks (for example, SONET and SDH networks), and subsequently, in optical networks with wavelength routing (WRN), packet switching (OPS), or burst switching (OBS) [1,2].

Wavelength routing networks arose as a development of peer-to-peer when routing functions were introduced in the photonic domain. The success of these networks was such that today there are already many of them deployed and interconnected [1]. OPS and OBS networks use the time domain to share network resources, and thus, achieve statistical multiplexing gains. Consequently, OPS and OBS achieve improved spectrum utilization when compared with WRN networks. However, OPS networks are still seen as networks for the long-term as the technologies necessary for its implementation are still in the maturing stage, while OBS networks, although they have been released commercially, have not found success in the marketplace. WRN networks are still the most viable solution, currently used to transport large amounts of information over long distances and, therefore, much of the research in optical networks is still directed to them. In addition to the time domain, explored in the OPS and OBS technology, the spectral domain can be naturally operated to achieve greater flexibility and granularity transmission efficiency for WRN networks. The current optical communication systems use signals with On-Off Keying encoding (OOK), where 0 and 1 bits are encoded respectively by the presence and absence of light [1]. Despite its simplicity to be generated and detected, this encoding has a low 
spectral efficiency which limits the capacity utilization of optical fibers. To illustrate this fact, it is sufficient to note that a WDM commercial system with $10 \mathrm{Gbps}$ channels allocated to a band of $50 \mathrm{GHz}$ has a spectral efficiency of only $0.2 \mathrm{bps} / \mathrm{Hz}(10 \mathrm{Gbps} / 50 \mathrm{GHz})$; whereas the Shannon theorem states that this efficiency could reach levels of $7 \mathrm{bps} / \mathrm{Hz}$ [1] in optical systems.

According to Reference [1], so that the efficiency of optical systems approach this theoretical limit, it becomes necessary to use more sophisticated ways of using the available spectrum. One solution would be the use of advanced modulation formats and digital equalization in the electrical field, as these provide much higher spectral efficiencies than OOK systems. Some studies advanced in this direction [1], however, the insistence on the rigid spectral granularity of WDM systems makes it excessively difficult to maintain an efficient spectrum allocation for optical networks. This is because it is difficult to match the network resources and bandwidth necessary to meet the reporting requirements in an optical network with a hard spectrum. It is easy to see that in a system with different transmission rates, there is no single spectral spacing that is great for all data rates and the distances involved. These requirements suggest that optical networks are more flexible in relation to the data rate, more nimble, reconfigurable, and efficient on the allocation of resources.

Given this limitation due to the rigidity of the WDM grid, several recent studies [3-17] evaluated the use of optical network architectures that occupy the bandwidth in a more flexible, efficient, and scalable way, such as Spectrum-Sliced Elastic Optical Path Networks (SLICE), or simply Elastic Optical Networks (EONs) [18].

In this context, this paper proposes a new algorithm based on subsequent optimizations-through a new modified MILP (Mixed Integer Linear Programming) formula-to reduce the power consumption of an Elastic Optical Network-during its plan-while maintaining the blocking probability below a predefined threshold.

The following Sections are organized as follows. Section 2 presents the basic characteristics of Elastic Optical Networks. Section 3 provides an overview of the characteristics of the analyzed problem. Section 4 presents the basic optimization model used as a reference. In Section 5, the proposed power consumption model is presented. A modified formulation is introduced in Section 6. Section 7 presents the MILP-based algorithm and the simulations and results are discussed in Section 8. Finally, the conclusions are presented in Section 9, followed by references.

\section{Elastic Optical Networks}

SLICE networks use the O-OFDM modulation technology, allowing the allocation of optical channels with variable bandwidth through the use of appropriate optical tunable filters and routers. The essential idea is to not use a fixed grid of wavelengths (thus termed gridless). In addition, they must possess management and network elements capable of providing flexible bandwidth to the optical paths such that they can be allocated to any bandwidth, and can expand and contract freely according to the traffic volume and user requests.

These novel networks were introduced in Reference [18] and are also known in the literature as networks without a gridded, adaptive, spectrum-flexible, elastic optical paths, or simply Elastic Optical Networks (EONs). In them, the fiber spectrum is treated as a continuing resource, allowing greater compression and efficiency in the use of it. Basically, the optical path can be allocated to any continuous frequency range and must be separated from other optical paths by a guard band called Filter Guard Band (FGB). Wavelength-Selective Switches (WSS) and variable bandwidth optical filters are used for switching and filtering the flexible bandwidths [19]. Thus, along with the route, a sufficient amount of spectrum must be allocated for the creation of an optical path with appropriate transmission capacity. Finally, transmitters and receivers need to also be adapted to the flexibility of the spectrum usage available on the EON architecture. 


\section{Problem Characterization}

Currently, some references in the literature emphasize the importance of energy efficiency in the operation of elastic optical networks, like References [20-26]. However, none of them evaluate the consumption of the network that is subject to adaptive modulation and the simultaneously spontaneous emission noise.

\subsection{Adaptive-Modulation}

Several authors have shown that adaptive-modulation provides considerable savings of elastic optical network resources [27-29] when considering the signal range and link distance to be traveled. However, the first to assess the real impact of the different modulation formats in the planning of the network was Reference [30]. They considered, besides the adaptive-modulation, the effect of spontaneous emission noise generated by the span between optical amplifiers. Table 1 exemplifies the characteristics (spectral efficiency and data rate) of the six types of OFDM modulation.

Table 1. The modulations characteristics.

\begin{tabular}{ccc}
\hline Modulation Format & Spectral Efficiency (bps/Hz) & Spectral Capacity (Gbps) \\
\hline BPSK & 1 & 12.5 \\
QPSK & 2 & 25 \\
8-QAM & 3 & 37.5 \\
16-QAM & 4 & 50 \\
32-QAM & 5 & 62.5 \\
64-QAM & 6 & 75 \\
\hline
\end{tabular}

The lower the spectral efficiency of the modulation, the larger the range and the lower the data rate. Thus, the necessary bandwidth for transmission will be major. It characterizes the trade-off between range and spectrum usage.

\subsection{Amplified Spontaneous Emission Noise}

In Reference [30], a MILP formulation, which considers the effect of amplified spontaneous emission noise (ASE noise) generated by the optical span between amplifiers, is presented. It is assumed that the performance of transmission systems are limited by two factors: (I) The accumulation of amplified spontaneous emission noise when a signal propagates through a link; and (II) the maximum finite power available for each channel, represented by the maximum threshold of the total noise emitted.

\subsection{Power Consumption}

In this paper, the concepts of adaptive modulation and spontaneous emission noise are integrated into the concept of power consumed by the EON elements in a new MILP formulation, which will be described in Section 6.

\section{Optimization Model (RMLSA)}

While performing a network planning with an emphasis on resource optimization, a SLICE network with multiple modulation formats provides a trade-off between the range of the optical path, the modulation format, and the number of slots demanded on the network. An appropriate model to quantify this trade-off was presented in Reference [30] which we will call "traditional MILP" for comparison purposes. Additionally, a model to measure the total power consumed on the network, described below, will be added to the traditional MILP. 


\section{Power Consumption Model}

The power consumption model proposed in this paper considers amplifiers, transceivers, and optical cross-connects (OXCs) as components of the physical layer with the greatest influence on the optimization, as in Reference [23-25]. In this context, the total power consumed by the optical layer is given by the following:

$$
\mathrm{PC}_{\text {total }}=\mathrm{PC}_{\mathrm{OFDM}}+\mathrm{PC}_{\mathrm{OXC}}+\mathrm{PC}_{\mathrm{AMP}}
$$

The power consumed by the transceivers $\left(\mathrm{PC}_{\mathrm{OFDM}}\right)$ is given by the following equation [24]:

$$
\mathrm{PC}_{\mathrm{OFDM}}=1.683 \times \mathrm{TR}+91.333[\mathrm{~W}],
$$

where TR is the transceiver transmission rate for the used modulation. The power consumed by the optical cross-connects $\left(\mathrm{PC}_{\mathrm{OXC}}\right)$ is given by [23] the following:

$$
\mathrm{PC}_{\mathrm{OXC}}=\mathrm{N} \times 85+\alpha \times 100+150[\mathrm{~W}],
$$

where $\mathrm{N}$ is the physical degree of the OXC node (the number of connected fibers to the node) and $\alpha$ is the virtual degree of the OXC (the number of channels that can be inserted/deleted). Finally, the power consumed by each amplifier ( $\mathrm{PC}_{\mathrm{AMP}}$ ) is $30 \mathrm{~W}$ for each direction of the flow in the fiber [24]. Using these equations, it is possible to measure the total power consumed in the network while maximizing the amount of served traffic on the network.

\section{Modified Formulation}

Once the primary objective of the traditional formulation, which is to get the highest value for the attended demand $\left(\max \left(C_{a}\right)\right)$, that is, to reduce to the maximum the blocking probability $\left(P_{\text {block }}\right)$, is achieved, the next step is to minimize the power consumed in the network using that data as the input to the model. For this, it will be introduced as a new model, which we will call the "modified MILP", described below.

\subsection{Notation}

- $\quad \mathrm{i}$ and $\mathrm{j}$ denote the originating and terminating nodes, respectively, of a variable bandwidth (in terms of slots) lightpath.

- $\quad \mathrm{m}$ and $\mathrm{n}$ denote the endpoints of a physical link in the network.

- $\quad \mathrm{z}$ denotes the modulation format.

\subsection{Given}

- $\quad \mathrm{N}$ : the number of nodes in the network.

- $\quad \Lambda^{\mathrm{ij}}$ : the traffic matrix element, which denotes the traffic intensity (in bps) demanded from the source node $i$ to the destination node $j$.

- $\mathrm{d}_{\mathrm{mn}}$ : the physical topology, which represents the distance of the fiber interconnecting node $\mathrm{m}$ to $\mathrm{n}$.

- $\quad$ MS: the capacity of each fiber. The maximum number of slots per link.

- GC: the filter guard band, which is the minimum spectrum width between wavebands (in terms of the number of slots).

- $\Omega$ : Slot width, which informs the slot width in Hz.

- $\mathrm{E}(\mathrm{z}) \mathrm{max}$ : the limit of the total cumulative spontaneous emission noise on a signal with " $\mathrm{z}$ " modulation format.

- 1 : the length of the fiber span between two amplifiers.

- $\quad f(1)$ : the spontaneous emission noise produced by an amplifier to compensate a span with length 1 .

- $\quad \varepsilon_{\mathrm{z}}$ : the spectral efficiency (bps/Hz) for " $\mathrm{z}$ " modulation format.

- $\mathrm{K}$ : a larger number to be used to make some integer variables. 
- $\quad P_{\mathrm{OXC}_{m}}$ : the power consumed by $\mathrm{OXC}_{\mathrm{m}}$.

- $\quad P C_{\text {amp: }}$ the power consumed by each optical amplifier.

- $\mathrm{N}_{\mathrm{amp}}$ : the number of amplifiers on the network.

- $G f_{m n}$ : the binary variable used to account the degree of the node.

- $N_{m}$ : the physical degree of node $\mathrm{m}$ (number of connected fibers to the node).

- $\quad \alpha$ : the virtual degree of OXC (number of channels that can be inserted/deleted).

- The blocking probability:

$$
\mathrm{P}_{\text {block }}=1-\left(\max \left(\mathrm{C}_{\mathrm{a}}\right) / \mathrm{C}_{\mathrm{r}}\right),
$$

where $\max \left(C_{a}\right)$ is the attended demand (Gbps) obtained by running the traditional MILP and $C_{r}$ is the total requested demand (Gbps) on the network.

\subsection{Variables}

- Lightpath bandwidth $b_{\mathrm{ijz}}$ : the bandwidth in terms of the number of slots of an elastic lightpath from node $i$ to node $j$ with " $z$ " modulation format.

- Physical topology route $P_{m n}^{\mathrm{ijz}}$ : the amount of bandwidth that the lightpath from node $i$ to node $j$ with " $z$ " modulation format uses in fiber link m-n.

- $\quad f(i, j, z)$ : the total cumulative spontaneous emission noise of a lightpath from node $i$ to node $j$ with the " $\mathrm{z}$ " modulation format.

- A binary variable $A_{\mathrm{mn}}^{\mathrm{ijz}}$ to indicate whether the lightpath from node $\mathrm{i}$ to node $\mathrm{j}$ with " $\mathrm{z}$ " modulation format passes through a link $m-n$. $A_{m n}^{\mathrm{ijz}}$ equals 1 if $\mathrm{P}_{\mathrm{mn}}^{\mathrm{ijz}}>0$ and equals 0 if $\mathrm{P}_{\mathrm{mn}}^{\mathrm{ijz}}=0$.

- $\mathrm{M}_{\mathrm{ijz}}$ : a binary variable to indicate which of the " $\mathrm{z}$ " modulation formats was used on the lightpath from node $i$ to node $j$.

- $\mathrm{TR}_{\mathrm{ijz}}$ : the transmission rate of the transceiver which sends the optical path $(\mathrm{i}, \mathrm{j})$ with modulation " $\mathrm{z}$ ".

- $\quad \mathrm{PC}_{\mathrm{OFDM}_{\mathrm{ijz}}}$ : the power consumed by each transceiver BV (Bandwidth Variable).

- $\quad P C_{\text {total }}$ : the total power consumed.

\subsection{Modified MILP Formulation}

Minimize:

$$
\mathrm{PC}_{\text {total }}=\sum_{\mathrm{m}} \mathrm{PC}_{\mathrm{OXC}_{\mathrm{m}}}+\sum_{\mathrm{ij}}\left[\sum_{\mathrm{z}} \mathrm{PC}_{\mathrm{OFDM}_{\mathrm{ijz}}}\right]+\mathrm{N}_{\mathrm{amp}} \times \mathrm{PC}_{\mathrm{amp}}
$$

Subject to:

$$
\begin{gathered}
\sum_{\mathrm{n}} \mathrm{P}_{\mathrm{mn}}^{\mathrm{ijz}}-\sum_{\mathrm{n}} \mathrm{P}_{\mathrm{nm}}^{\mathrm{ijz}}=\left\{\begin{array}{rr}
\mathrm{b}_{\mathrm{ijz}} & \text { if } \mathrm{m}=\mathrm{i} \\
-\mathrm{b}_{\mathrm{ijz}} & \text { if } \mathrm{m}=\mathrm{j} \\
0 & \text { if } \mathrm{m} \neq \mathrm{i}, \mathrm{j}
\end{array} \quad \forall \mathrm{m}, \mathrm{i}, \mathrm{j}, \mathrm{z}\right. \\
\sum_{\mathrm{ij}}\left(\mathrm{P}_{\mathrm{mn}}^{\mathrm{ijz}}+\mathrm{FGB} \times \mathrm{A}_{\mathrm{mn}}^{\mathrm{ijz}}\right) \leq \mathrm{MS} \quad \forall \mathrm{m}, \mathrm{n}, \mathrm{z} \\
\mathrm{A}_{\mathrm{mn}}^{\mathrm{ijz}} \geq \mathrm{P}_{\mathrm{mn}}^{\mathrm{ijz}} / \mathrm{M} \forall \mathrm{i}, \mathrm{j}, \mathrm{m}, \mathrm{n}, \mathrm{z} \\
\mathrm{M}_{\mathrm{ijz}} \geq \mathrm{b}_{\mathrm{ijz}} / \mathrm{M} \quad \forall \mathrm{i}, \mathrm{j}, \mathrm{z} \\
\sum_{\mathrm{z}} \mathrm{M}_{\mathrm{ijz}} \leq 1 \quad \forall \mathrm{i}, \mathrm{j} \\
\mathrm{b}_{\mathrm{ijz}} \geq \mathrm{M}_{\mathrm{ijz}} \times \wedge_{\mathrm{ij}} \times\left(1 / \varepsilon_{\mathrm{z}}\right) \times(1 / \Omega) \forall \mathrm{i}, \mathrm{j}, \mathrm{z} \\
\sum_{\mathrm{mn}}\left[\left(\mathrm{A}_{\mathrm{mn}}^{\mathrm{ijz}} \times \mathrm{d}_{\mathrm{mn}}\right) / \mathrm{l}\right] \times \mathrm{f}(\mathrm{l})=\mathrm{f}(\mathrm{i}, \mathrm{j}, \mathrm{z}) \forall \mathrm{i}, \mathrm{j}, \mathrm{z} \\
\mathrm{f}(\mathrm{i}, \mathrm{j}, \mathrm{z}) \leq \mathrm{E}(\mathrm{z}) \mathrm{max} \forall \mathrm{i}, \mathrm{j}, \mathrm{z} \\
\mathrm{PC}_{\mathrm{OXC}}=\mathrm{N}_{\mathrm{m}} \times 85+\alpha \times 100+150[\mathrm{~W}] \forall \mathrm{m} \\
\mathrm{Gf}_{\mathrm{mn}}=\left\{\begin{array}{cc}
1, \quad \mathrm{D}_{\mathrm{mn}}>0 \\
0, \quad
\end{array} \quad \forall \mathrm{m}, \mathrm{n}\right.
\end{gathered}
$$




$$
\begin{gathered}
\mathrm{N}_{\mathrm{m}}=\sum_{\mathrm{n}} \mathrm{Gf}_{\mathrm{mn}} \quad \forall \mathrm{m} \\
\mathrm{PC}_{\mathrm{OFDM}_{\mathrm{ijz}}=} 1.683 \times \mathrm{TR}_{\mathrm{ijz}}+\mathrm{M}_{\mathrm{ijz}} \times 91.333[\mathrm{~W}] \\
\mathrm{TR}_{\mathrm{ijz}}=\mathrm{M}_{\mathrm{ijz}} \times \varepsilon_{\mathrm{z}} \times \Omega \quad \forall \mathrm{i}, \mathrm{j}, \mathrm{z} \\
\mathrm{PC} \mathrm{amp}=30[\mathrm{~W}] \\
\mathrm{N}_{\mathrm{amp}}=\sum_{\mathrm{mn}} \mathrm{d}_{\mathrm{mn}} / \mathrm{l}_{\mathrm{amp}}
\end{gathered}
$$

\section{MILP-Based Algorithm}

In this Section, an algorithm (Algorithm 1) is presented for solving various optimization goals using the MILP formulations previously presented in the subsequent steps (min MS, max Ca, min $P_{\text {total }}$ ), where MS is the maximum number of sub-carriers in a physical network link.

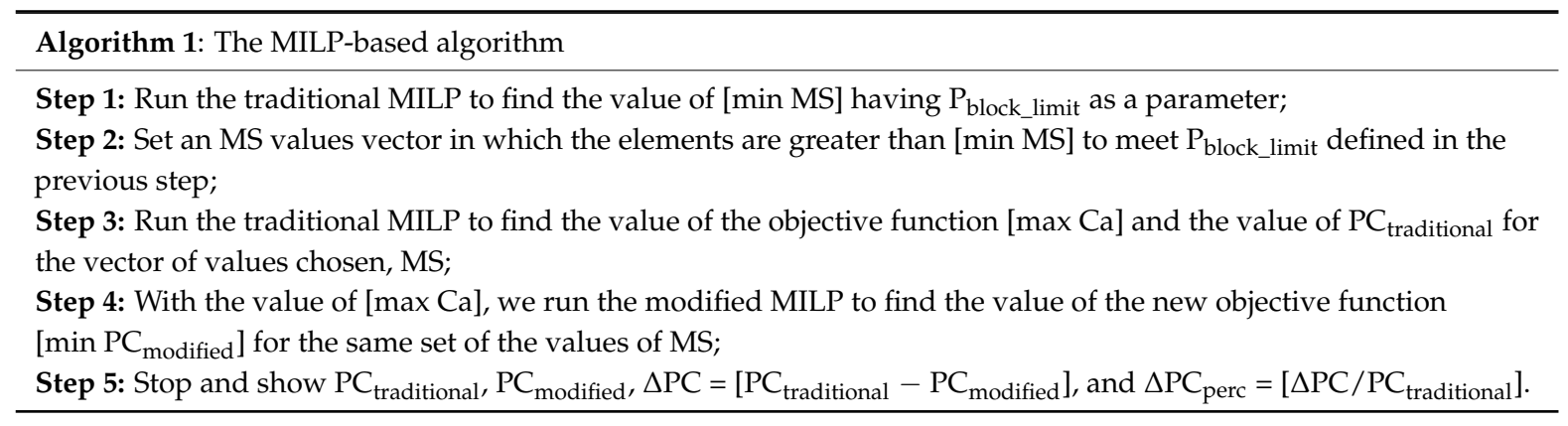

In Steps 1 and 2, the vector of the MS values to be considered in view of the predefined maximum blocking probability ( $\mathrm{P}_{\text {block_limit }}$ ) is defined. Step 3 obtains the max Ca value-to be used as a parameter in Step 4 -and the amount of power consumed by the traditional MILP ( $P C_{\text {traditional }}$ ). In Step 4, the value of the power consumed with the modified MILP ( $\mathrm{PC}_{\text {modified }}$ ) is obtained. Finally, in Step 5 the absolute power savings $(\triangle \mathrm{PC})$ and the power savings percentage $(\triangle \mathrm{PC}$ perc $)$ on the network is calculated.

\section{Simulations and Results}

The simulations were made in small networks (6NET) and large networks (NSFNET, ARPANET, Brazilian and COST239) using the AMPL programming language under the IBM simulation platform ILOP CPLEX Optimization Studio v.12.5, with an Intel Core processor I5-3230M (2.60 GHz), 4 G RAM, and a Windows 10 operational system, (64-bit). They were limited to $5 \mathrm{~min}$ to prevent high simulation times on large networks. The results are presented below.

\subsection{Small Network (6NET)}

To evaluate the effectiveness of the proposed problem, we used two physical topologies, shown in Figure 1 below.

It is assumed that there is a pair of bidirectional fibers on each link and a distance of $1000 \mathrm{~km}$ between nodes. The guard band is FGB $=1$ slot and the spectral width of the slot is $\Omega=12.5 \mathrm{GHz}$. The requested traffic demand is uniform and equals $100 \mathrm{Gbps}$ for each pair source-destination. The distance between amplifiers is $1=100 \mathrm{~km}$ with normalized spontaneous emission noise, $\mathrm{f}(\mathrm{l})=1$ (noise unit). Three different modulation formats were used ( $\mathrm{M}_{1}=\mathrm{BPSK}, \mathrm{M}_{2}=\mathrm{QPSK}$ and $\mathrm{M}_{3}=16-\mathrm{QAM}$ ) with spectral efficiencies $\varepsilon_{1}=1, \varepsilon_{2}=2$ and $\varepsilon_{3}=4(\mathrm{bps} / \mathrm{Hz})$, where the noise threshold for each modulation is $\mathrm{E}(1)_{\max }=40$, and $\mathrm{E}(2)_{\max }=30$, and $\mathrm{E}(3)_{\max }=20$ (noise units). The virtual degree of $\mathrm{OXC}$ $(\alpha)$ was considered to be equal to 3 .

Figure 2 shows the total power consumed in the function of the number of slots per link in two different scenarios: with traditional MILP, disregarding the minimization of power, and the modified MILP. For 6 NET, the maximum blocking probability was defined at $20 \%$, resulting in the restriction 
of MS as being $\geq 7$. Thus, the demand satisfied according to the capacity of the links is maintained above the blocking threshold due to the sequencing of the proposed algorithm. It is important to emphasize that, as the MS increases, the blocking probability decreases to become zero in MS = 13 for 6 NET (this point we shall call $\mathrm{MS}_{\text {zero }}$ ). It can be seen in Figure 2a that, from this point, the power consumed in the network tends to decrease due to the relaxation of the restriction related to the fiber capacity arising from the increase in MS. For $6 \mathrm{MESH}$, the maximum blocking probability was defined at $0 \%$ with $M S \geq 2$. The results for this network are shown in Figure $2 b$.

With this new approach for $6 \mathrm{NET}$, the network power saving gets to be of the order of $1.3 \mathrm{KW}$ at the points where MS $\geq 35$, which represents a percentage saving of $10.5 \%$. The average saving for the defined MS vector is $6.6 \%$. Already for $6 \mathrm{MESH}, 1 \mathrm{KW}$ is saved with $\mathrm{MS} \geq 35$, which results in a $5.3 \%$ saving and, for the defined vector, a $6.83 \%$ average saving. These prove the efficiency of the proposed modified MILP formulation for small networks.

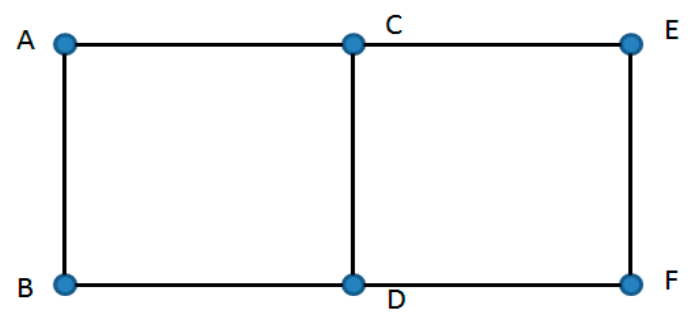

(a)

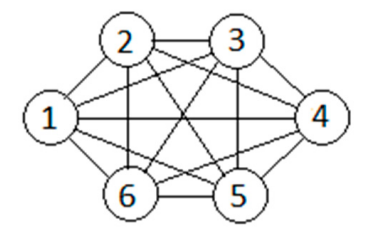

(b)

Figure 1. The simulation network's physical topologies: (a) 6NET; (b) 6MESH.

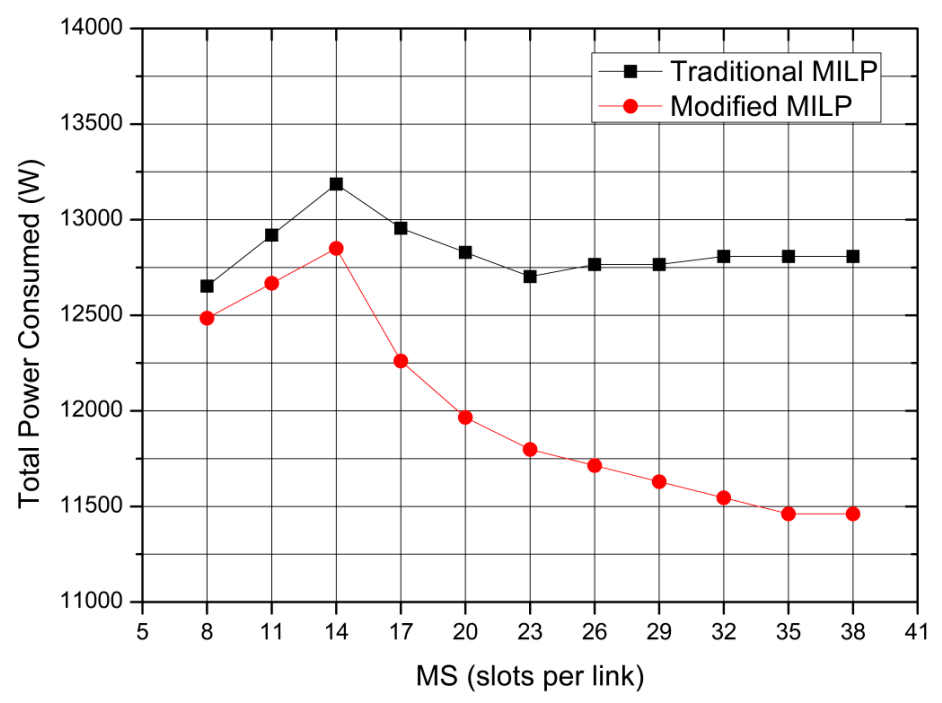

(a)

Figure 2. Cont. 


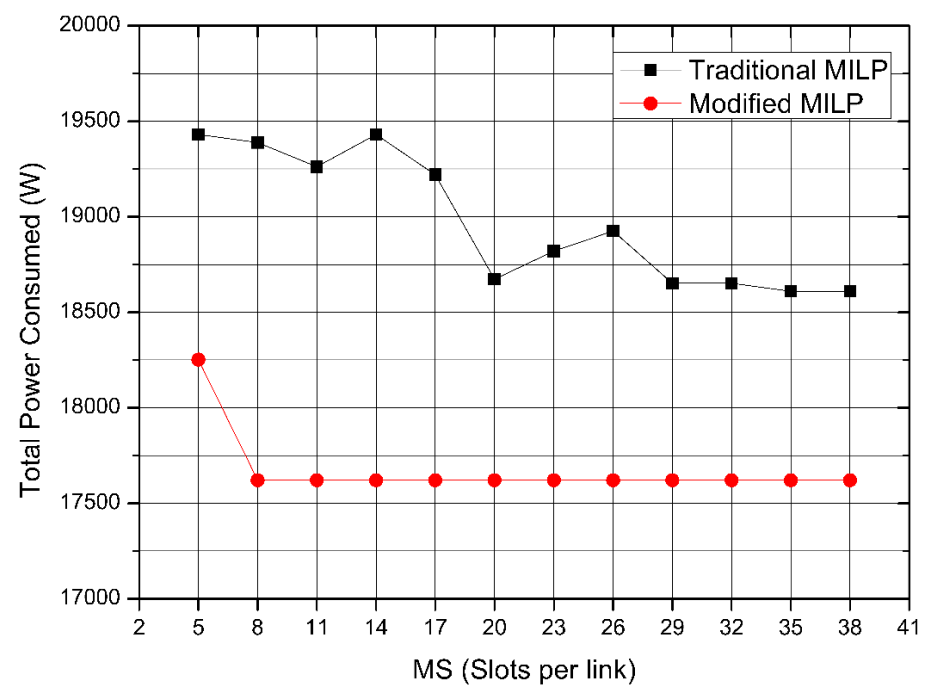

(b)

Figure 2. The power consumed in the function of the number of slots per enlace: (a) on 6NET; (b) on $6 \mathrm{MESH}$.

\subsection{Moderate Sized Networks}

In this Section, the results of the simulations in the four hypothetical moderate networks are presented (Figure 3).

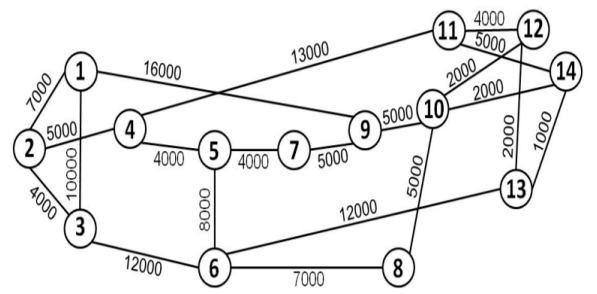

(a)

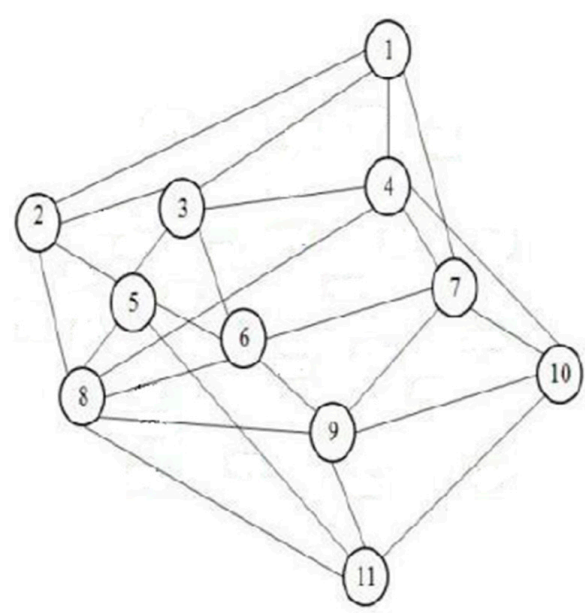

(c)

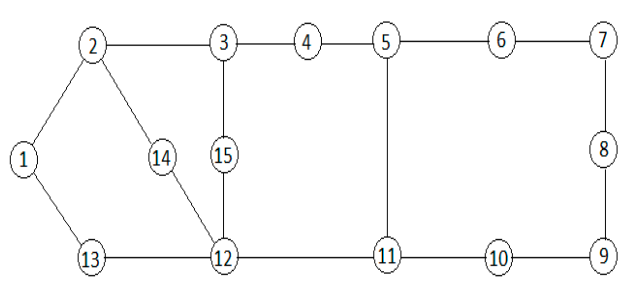

(b)

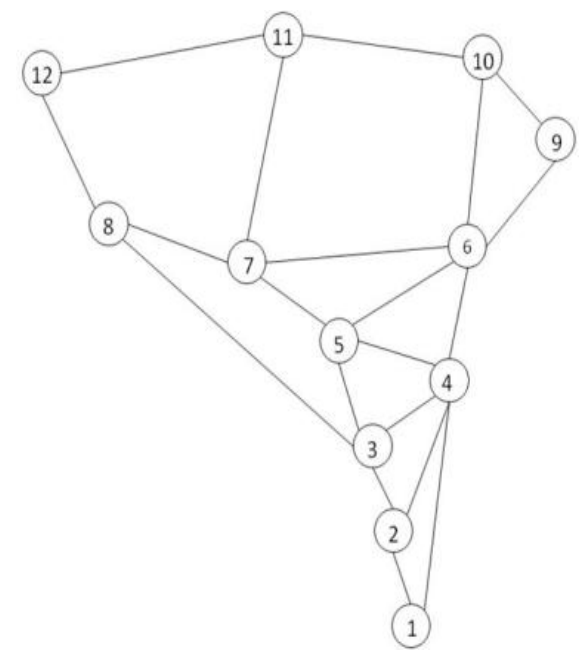

(d)

Figure 3. The simulation network's physical topologies: (a) NSFNET; (b) ARPANET; (c) COST239; (d) BRAZILIAN. 
For NSFNET, the noise limits are $\mathrm{E}(1)_{\max }=800, \mathrm{E}(2)_{\max }=600$, and $\mathrm{E}(3)_{\max }=300$ (noise units) and the traffic demand, shown in Table 2, is the same as that defined in Reference [30].

Table 2. The traffic demand for the NSFNET network (Gbps).

\begin{tabular}{ccccccccccccccc}
\hline Node & $\mathbf{1}$ & $\mathbf{2}$ & $\mathbf{3}$ & $\mathbf{4}$ & $\mathbf{5}$ & $\mathbf{6}$ & $\mathbf{7}$ & $\mathbf{8}$ & $\mathbf{9}$ & $\mathbf{1 0}$ & $\mathbf{1 1}$ & $\mathbf{1 2}$ & $\mathbf{1 3}$ & $\mathbf{1 4}$ \\
\hline 1 & & 100 & 100 & 100 & 100 & 100 & 200 & 200 & 100 & 200 & 50 & 200 & 100 & 200 \\
2 & 200 & & 50 & 100 & 200 & 200 & 200 & 100 & 50 & 200 & 200 & 100 & 200 & 50 \\
3 & 200 & 100 & & 200 & 200 & 50 & 100 & 200 & 200 & 200 & 100 & 50 & 200 & 200 \\
4 & 100 & 200 & 50 & & 200 & 100 & 200 & 200 & 50 & 100 & 200 & 200 & 200 & 100 \\
5 & 50 & 200 & 200 & 100 & & 200 & 50 & 200 & 100 & 200 & 200 & 50 & 100 & 200 \\
6 & 200 & 200 & 100 & 50 & 200 & & 200 & 100 & 200 & 50 & 200 & 100 & 200 & 200 \\
7 & 50 & 100 & 200 & 200 & 200 & 100 & & 50 & 200 & 200 & 100 & 200 & 50 & 200 \\
8 & 100 & 200 & 200 & 50 & 100 & 200 & 200 & & 200 & 100 & 50 & 200 & 200 & 100 \\
9 & 200 & 50 & 200 & 100 & 200 & 200 & 50 & 100 & & 200 & 200 & 200 & 100 & 50 \\
10 & 200 & 200 & 100 & 200 & 50 & 200 & 100 & 200 & 200 & & 50 & 100 & 200 & 200 \\
11 & 200 & 100 & 50 & 200 & 200 & 100 & 200 & 50 & 200 & 100 & & 200 & 200 & 50 \\
12 & 100 & 200 & 200 & 200 & 100 & 50 & 200 & 200 & 100 & 200 & 50 & & 200 & 100 \\
13 & 200 & 200 & 50 & 100 & 200 & 200 & 200 & 100 & 50 & 200 & 200 & 100 & & 200 \\
14 & 50 & 200 & 100 & 200 & 200 & 50 & 100 & 200 & 200 & 200 & 100 & 50 & 200 & \\
\hline
\end{tabular}

Already for ARPANET, the noise limits are $\mathrm{E}(1)_{\max }=1200, \mathrm{E}(2)_{\max }=800$, and $\mathrm{E}(3)_{\max }=400$ (noise units). The length of the links $\left(\mathrm{d}_{\mathrm{mn}}\right)$ is uniform and equals $1000 \mathrm{~km}$ and the traffic demand for each source-destination pair was defined randomly between 50 and 200 Gbps. For COST239, the noise limits are $\mathrm{E}(1)_{\max }=20, \mathrm{E}(2)_{\max }=10$, and $\mathrm{E}(3)_{\max }=5$ (noise units). The length of the links $\left(\mathrm{d}_{\operatorname{mn}}\right)$ are non-uniform, as shown in Table 3 and the traffic demand for each source-destination pair was defined randomly between 100 and $300 \mathrm{Gbps}$. For the BRAZILIAN network, the noise limits are $\mathrm{E}(1)_{\max }=80$, $\mathrm{E}(2)_{\max }=40$, and $\mathrm{E}(3)_{\max }=20$ (noise units). The length of the links $\left(\mathrm{d}_{\mathrm{mn}}\right)$ is uniform and equal $2000 \mathrm{~km}$, and the required demand for each source-destination pair was defined randomly between 50 and 300 Gbps. Other parameters, for now unspecified, are the same as those used for the small networks in the previous Section.

Table 3. The length of the links on COST239 (km).

\begin{tabular}{|c|c|c|c|c|c|c|c|c|c|c|c|}
\hline Node & 1 & 2 & 3 & 4 & 5 & 6 & 7 & 8 & 9 & 10 & 11 \\
\hline 1 & & 1300 & 700 & 300 & & & 700 & & & & \\
\hline 2 & 1300 & & 500 & & 300 & & & 400 & & & \\
\hline 3 & 700 & 500 & & 600 & 200 & 300 & & & & & \\
\hline 4 & 300 & & 600 & & & & 300 & 1000 & & 600 & \\
\hline 5 & & 300 & 200 & & & 200 & & 300 & & & 900 \\
\hline 6 & & & 300 & & 200 & & 700 & 400 & 300 & & \\
\hline 7 & 700 & & & 300 & & 700 & & & 500 & 300 & \\
\hline 8 & & 400 & & 1000 & 300 & 400 & & & 600 & & 800 \\
\hline 9 & & & & & & 300 & 500 & 600 & & 700 & 300 \\
\hline 10 & & & & 600 & & & 300 & & 700 & & 800 \\
\hline 11 & & & & & 900 & & & 800 & 300 & 800 & \\
\hline
\end{tabular}

Maximum blocking probability was set to $0 \%$, that is, that all requests must be met, resulting in $\mathrm{MS}_{\text {NSFNET }} \geq \mathrm{MS}_{\text {NSFNETzero }}=60, \mathrm{MS}_{\text {ARPANET }} \geq \mathrm{MS}_{\text {ARPANETzero }}=111$, MS $_{\text {BRASILEIRA }}$ $\geq \mathrm{MS}_{\text {BRASILEIRAzero }}=105$, and $\mathrm{MS}_{\mathrm{COST} 239} \geq \mathrm{MS}_{\mathrm{COST} 239 \text { zero }}=51$. For a joint analysis, the vector MS $=(140-300)$ for the four networks was defined. Thus, Figure 4 shows the absolute power savings according to the number of slots per link for these networks. 


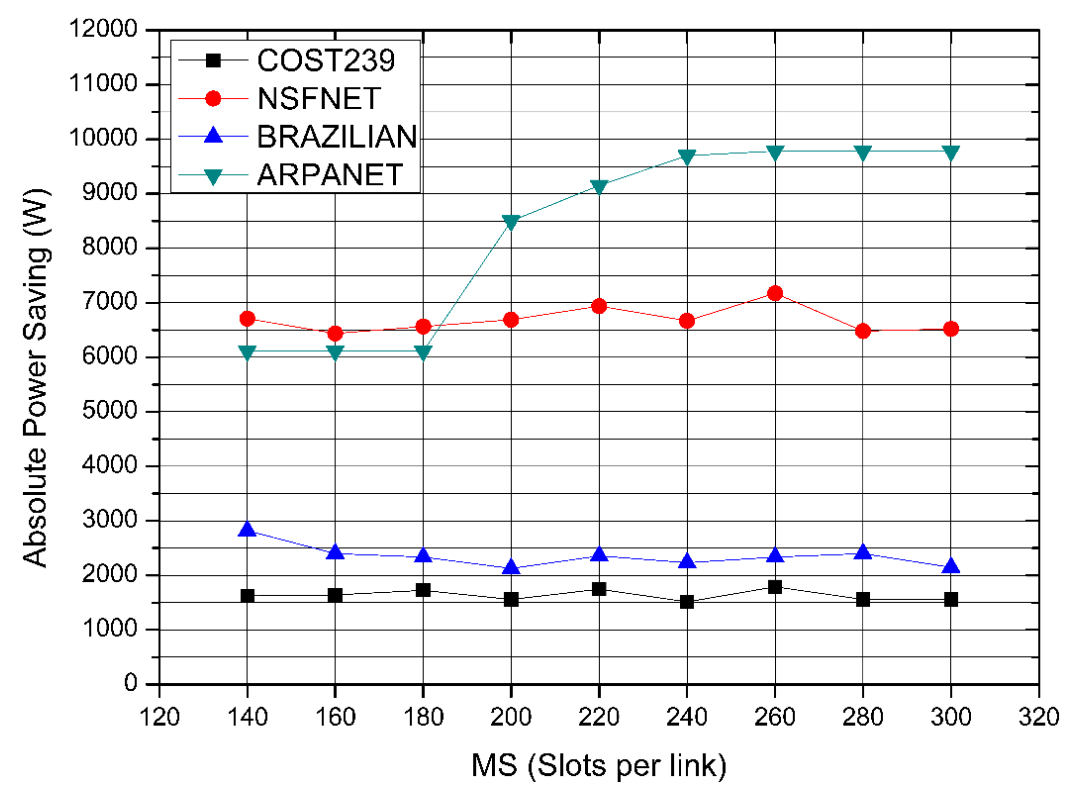

Figure 4. The absolute power savings on the four networks.

Figure 5 already shows the power savings percentage according to the number of slots per link for each network separately and together through the average profile.

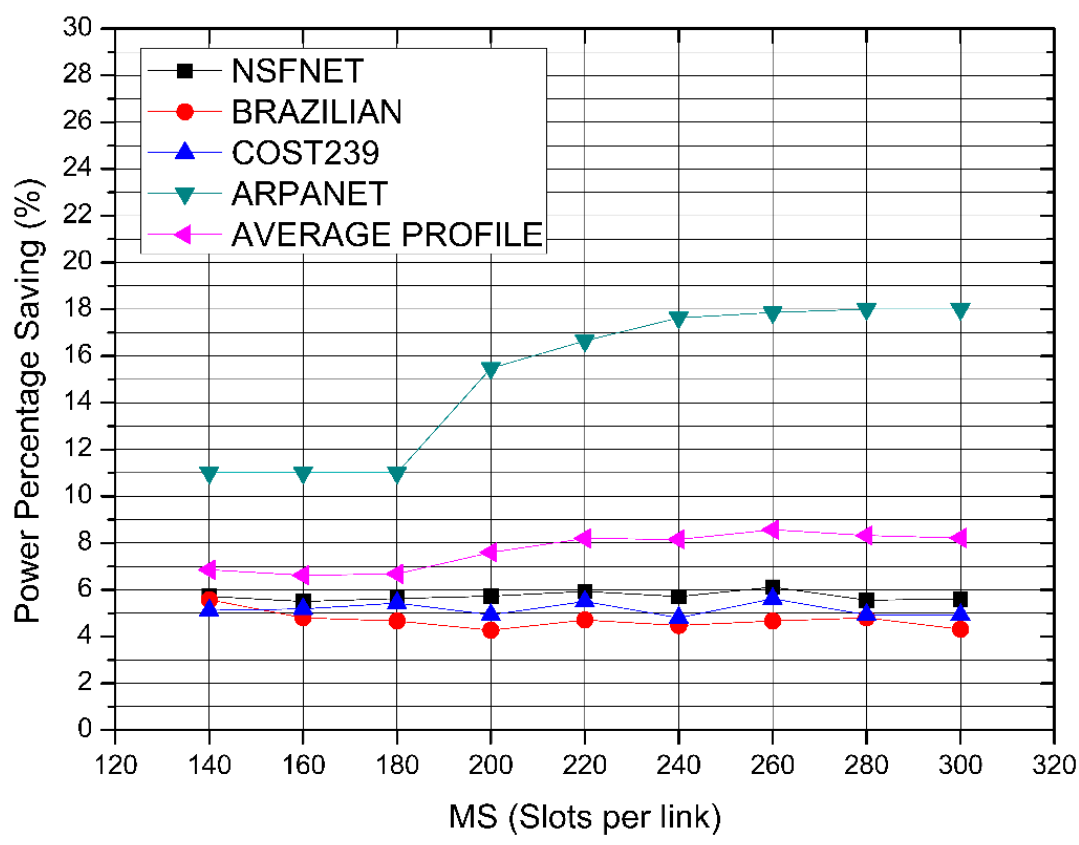

Figure 5. The power saving percentage on each network and the average profile.

With the implementation of the MILP-based algorithm, the maximum power savings on each network is up to the order of 9.8 KW (ARPANET), 7.2 KW (NSFNET), $2.8 \mathrm{KW}$ (Brazilian), and 1.8 KW (COST239) at the points where MS $=260,260,140$, and 260, representing a savings percentage of $17.8 \%, 6.1 \%, 5.6 \%$, and $5.6 \%$, respectively. Through the average profile, it can be seen that the average percentage savings for the four networks together was $7.7 \%$, proving the efficiency of the proposed modified MILP formulation for moderately sized networks. 
Note that if the maximum blocking probability was set to $40 \%$, for example, implying $\mathrm{MS}_{\text {NSFNET }} \geq 19, \mathrm{MS}_{\text {ARPANET }} \geq 32, \mathrm{MS}_{\text {BRASILEIRA }} \geq 28$, and $\mathrm{MS}_{\mathrm{COST} 239} \geq 17$, this case was not analyzed due to the impossibility of the MILP to solve the problem within the simulation time limit ( $5 \mathrm{~min}$ ).

\section{Conclusions}

This paper presented a new modified MILP formulation and a sequential algorithm which aims to minimize the total power consumed by the components of an elastic optical network under adaptive modulation and physical layer constraints while maintaining the blocking probability below a predefined threshold.

The objectives of the proposed algorithm were reached and the simulations have proved the efficiency of the modified MILP model. Compared to the traditional one, it provides a maximum power percentage saving of $10.5 \%$ and an average power percentage saving of $6.6 \%$ in a small network (6NET), which means $1.3 \mathrm{KW}$ and $0.8 \mathrm{KW}$, respectively. For moderately sized networks, it obtained a maximum power savings of $17.8 \%$ and an average savings of $7.7 \%$, which represents $9.8 \mathrm{KW}$ and $4.8 \mathrm{KW}$, respectively.

It was concluded that the total power consumed was reduced due to the better fit of modulations by the modified formulation, once it optimizes the traffic distribution over the network in terms of efficiency. This approach contributes to the sustainability of the network since it requires fewer resources for its operation. Thus, it brings out the concept of green elastic optical networks (Green EONs), a recent theme that is only slightly explored in the literature. Its focus is on a sustainable and the as harmless as possible operation towards the environment.

For larger networks, the proposed formulation is not feasible since the complexity of the MILP increases rapidly. In this context, new heuristics/meta-heuristics and hybrid-algorithms should be developed in future works.

Author Contributions: I.Q. and K.A. conceived, designed and performed the experiments, analyzed the data and wrote the paper.

Conflicts of Interest: The authors declare no conflict of interest.

\section{References}

1. Ramaswami, R.; Sivarajan, K.; Sasaki, G. Optical Networks: A Practical Perspective; Mogan Kaufmann: Burlington, MA, USA, 2009.

2. Murthy, C.S.R.; Gurusamy, M. WDM Optical Networks: Concepts, Design, and Algorithms; Prentice Hall: Upper New Jersey River, NJ, USA, 2002.

3. Assis, K.D.R.; Queiroz, I.; Almeida, R.C.; Waldman, H. MILP formulation for resource optimization in Spectrum-Sliced Elastic Optical Path Networks. In Proceedings of the IEEE SBMO/IEEE MTT-S International Microwave \& Optoelectronics Conference (IMOC), Rio de Janeiro, Brazil, 4-7 August 2013; pp. 1-4.

4. Waldman, H.; Almeida, R.C.; Bortoletto, R.C.; Assis, K.D.R. Deadlock avoidance under incremental traffic in the elastic single link. In Proceedings of the 16th International Conference on Transparent Optical Networks (ICTON), Graz, Austria, 6-10 July 2014; pp. 1-4.

5. Assis, K.D.R.; Peng, S.; Almeida, R.C.; Waldman, H.; Hammad, A.; Santos, A.F.; Simeonidou, D. Network Virtualization Over Elastic Optical Networks With Different Protection Schemes. J. Opt. Commun. Netw. 2016, 8, 272-281. [CrossRef]

6. Assis, K.D.R.; Hammad, A.; Almeida, R.C., Jr.; Simeonidou, D. Approaches to Maximize the Open Capacity of Elastic Optical Networks. In Proceedings of the International Conference on Communications (ICC), Kuala Lumpur, Malaysia, 22-27 May 2016.

7. Favero, R.V.; Demanboro, A.C. Performance Analysis of Elastic Optical Network Comparing to Current Wavelength Division Multiplexing. IEEE Latin Am. Trans. 2016, 14, 1494-1498. [CrossRef]

8. Gkamas, V.; Christodoulopoulos, K.; Vergados, D.J.; Varvarigos, E. Energy-minimized design of IP over flexible optical networks. Int. J. Commun. Syst. 2017, 30, 7. [CrossRef] 
9. Hadi, M.; Pakravan, M.R. Energy-efficient fast configuration of flexible transponders and grooming switches in OFDM-based elastic optical networks. IEEE/OSA J. Opt. Commun. Netw. 2018, 10, 90-103. [CrossRef]

10. Papanikolaou, P.; Christodoulopoulos, K.; Varvarigos, E. Joint multi-layer survivability techniques for IP-over-elastic-optical-networks. J. Opt. Commun. Netw. 2017, 9, A85-A98. [CrossRef]

11. Hadi, M.; Pakravan, M.R. Energy-Efficient Transponder Configuration for FMF-based Elastic Optical Networks. IEEE Commun. Lett. 2018, 22, 970-973. [CrossRef]

12. Zhang, L.; Han, T.; Ansari, N. Energy-Aware Virtual Machine Management in Inter-datacenter Networks over Elastic Optical Infrastructure. IEEE Trans. Green Commun. Netw. 2018, 2, 305-315. [CrossRef]

13. Bandiri, S.Y.M.; Pimenta, T.C.; Spadoti, D.H. Adaptive Modulation and code Strategy to Reduce Energy Consumption in Elastic Optical Network. J. Microw. Optoelectron. Electromagn. Appl. (JMOe) 2018, 17, 65-84. [CrossRef]

14. Xiong, Y.; Shi, J.; Yang, Y.; Lv, Y.; Rouskas, G.N. Lightpath Management in SDN-Based Elastic Optical Networks With Power Consumption Considerations. J. Lightwave Technol. 2018, 36, 1650-1660. [CrossRef]

15. Natalino, C.; Chiaraviglio, L.; Idzikowski, F.; Wosinska, L.; Monti, P. Joint Optimization of Failure Management Costs, Electricity Costs, and Operator Revenue in Optical Core Networks. IEEE Trans. Green Commun. Netw. 2018, 2, 291-304. [CrossRef]

16. Saha, A.K.; Sambyo, K.; Bhunia, C.T. Energy efficient modelling of a network. China Commun. 2018, 15, 107-117. [CrossRef]

17. Huang, Y.; Cho, P.B.; Samadi, P.; Bergman, K. Power Excursion Mitigation for Flexgrid Defragmentation With Machine Learning. J. Opt. Commun. Netw. 2018, 10, A69-A76. [CrossRef]

18. Jinno, M.; Takara, H.; Kozicki, B.; Tsukishima, Y.; Sone, Y.; Matsuoka, S. Spectrum-efficient and scalable elastic optical path network: Architecture, benefits, and enabling technologies. Commun. Mag. IEEE 2009, 47, 66-73. [CrossRef]

19. Kozicki, B.; Takara, H.; Yoshimatsu, T.; Yonenaga, K.; Jinno, M. Filtering characteristics of highly-spectrum efficient spectrum-sliced elastic optical path (SLICE) network. In Proceedings of the National Fiber Optic Engineers Conference, San Diego, CA, USA, 22-26 March 2009; Optical Society of America: Washington, DC, USA, 2009; p. JWA43.

20. Vizcaíno, J.L.; Ye, Y.; Monroy, I.T. Energy efficiency analysis for flexible-grid OFDM-based optical networks. Comput. Netw. 2012, 56, 2400-2419. [CrossRef]

21. El-Gorashi, T.E.; Dong, X.; Elmirghani, J.M. Green optical orthogonal frequency-division multiplexing networks. Optoelectron. IET 2014, 8, 137-148. [CrossRef]

22. Wang, B.; Ho, P.H.; Lin, C.H. A novel energy-efficient transmission scheme in CO-OFDM elastic optical networks. J. Lightwave Technol. 2014, 32, 3380-3388. [CrossRef]

23. Vizcaino, J.L.; Ye, Y.; Lopez, V.; Jimenez, F.; Duque, R.; Musumeci, F.; Krummrich, P. Differentiated quality of protection to improve energy efficiency of survivable optical transport networks. In Proceedings of the Optical Fiber Communication Conference, Anaheim, CA, USA, 17-21 March 2013; Optical Society of America: Washington, DC, USA, 2013; p. OM3A-1.

24. Zhang, J.; Zhao, Y.; Zhang, J.; Mukherjee, B. Energy efficiency of IP-over-elastic optical networks with sliceable optical transponder. In Proceedings of the Optical Fiber Communication Conference, San Francisco, CA, USA, 9-13 March 2014; Optical Society of America: Washington, DC, USA, 2014; p. W3A-4.

25. Fallahpour, A.; Beyranvand, H.; Nezamalhosseini, S.A.; Salehi, J. Energy efficient routing and spectrum assignment with regenerator placement in elastic optical networks. J. Lightwave Technol. 2014, 32, 2019-2027. [CrossRef]

26. Chen, B.; Xie, W.; Zhang, J.; Jue, J.P.; Zhao, Y.; Huang, S.; Gu, W. Energy and spectrum efficiency with multi-flow transponders and elastic regenerators in survivable flexible bandwidth virtual optical networks. In Proceedings of the Optical Fiber Communication Conference, San Francisco, CA, USA, 9-13 March 2014; Optical Society of America: Washington, DC, USA, 2014; p. W2A-27.

27. Takagi, T.; Hasegawa, H.; Sato, K.I.; Sone, Y.; Kozicki, B.; Hirano, A.; Jinno, M. Dynamic routing and frequency slot assignment for elastic optical path networks that adopt distance adaptive modulation. In Proceedings of the Optical Fiber Communication Conference, Los Angeles, CA, USA, 6-10 March 2011; Optical Society of America: Washington, DC, USA, 2011; p. OTuI7. 
28. Palkopoulou, E.; Angelou, M.; Klonidis, D.; Christodoulopoulos, K.; Klekamp, A.; Buchali, F.; Tomkos, I. Quantifying spectrum, cost, and energy efficiency in fixed-grid and flex-grid networks [Invited]. J. Opt. Commun. Netw. 2012, 4, B42-B51. [CrossRef]

29. Nag, A.; Tornatore, M.; Mukherjee, B. Optical network design with mixed line rates and multiple modulation formats. J. Lightwave Technol. 2010, 28, 466-475. [CrossRef]

30. Assis, K.D.R.; Almeida, R.C.; Cartaxo, A.V.; dos Santos, A.F.; Waldman, H. Flexgrid optical networks design under multiple modulation formats. In Proceedings of the IEEE International Telecommunications Symposium (ITS), Sao Paulo, Brazil, 17-20 August 2014; pp. 1-5.

(C) 2018 by the authors. Licensee MDPI, Basel, Switzerland. This article is an open access article distributed under the terms and conditions of the Creative Commons Attribution (CC BY) license (http:// creativecommons.org/licenses/by/4.0/). 